\title{
Evaluation of In Vitro Synergistic Interaction of Miconazole and Polymyxin B Against Clinical Strains of Malassezia pachydermatis
}

\author{
Elisa Chiavassa ${ }^{*}$, Andrea Peano and Mario Pasquetti
} Settore di Parassitologia e Malattie Parassitarie, Dipartimento di Scienze Veterinarie, Università degli Studi di Torino,
Via Leonardo da Vinci 44, 10095 Grugliasco (Torino), Italy

\begin{abstract}
Malassezia pachydermatis is a yeast that is frequently involved as a secondary/perpetuating factor in canine otitis externa, along with numerous species of bacteria. As a result, otitis is generally treated with topical therapies using combinations of antifungal, antimicrobial and anti-inflammatory agents. The evaluation of the combined effect of drugs included in commercially available products is therefore important. In vitro synergy of polymyxin B and miconazole has been demonstrated against one strain type of $M$. pachydermatis. This study was aimed at investigating the in vitro interactions of these two agents against five clinical strains of this yeast. A chequerboard broth microdilution method was employed. We observed a synergistic action against all strains tested (fractional inhibitory concentration index comprised between 0.2 and 0.4 ). Our results indicate a strong therapeutic value for the association of these antimicrobial agents in the treatment of canine otitis externa caused by M. pachydermatis.
\end{abstract}

Keywords: Dog, Malassezia pachydermatis, miconazole, otitis externa, polymyxin B, synergy.

Canine otitis externa represents one of the most common diseases of multifactorial aetiology in veterinary practice [1]. Micro-organisms, including both bacteria and yeasts, are considered common perpetuating factors that can worsen and prevent the resolution of otitis [2]. Malassezia pachydermatis is the yeast isolated with the highest frequency from affected ears [3]. This organism is part of the commensal microflora of canine skin and ears, but it may become an opportunistic pathogen under favourable conditions, e.g. allergic, parasitic and immune-mediated diseases [1]. Topical therapy is the most popular and convenient way of treating canine otitis externa. Treatment usually involves the use of antibiotics, antifungals and anti-inflammatory agents, often included in a single formulation. A polyvalent product is indicated in first line treatment because bacteria and yeast are simultaneously present in a large number of cases [4]. Indepth evaluation of the combined effect of drugs included in marketed products is therefore important. Among the possible combinations available, a commonly used product in clinical practice contains polymyxin B (PMX) as an antibiotic and miconazole nitrate (MCZ) as an antifungal. This combination has proven to be effective for the treatment of dogs with otitis externa complicated by a number of bacterial and yeast species $[5,6]$. Such a positive response stems from the fact that PMX is effective against a broad variety of Gram-negative and, to a lesser extent, Grampositive bacteria, as well as having antifungal properties [7, 8], while MCZ is active against several pathogenic fungi,

*Address correspondence to this author at the Settore di Parassitologia e Malattie Parassitarie, Dipartimento di Scienze Veterinarie, Università degli Studi di Torino, Via Leonardo da Vinci 44, 10095 Grugliasco (Torino), Italy; Tel.: +39011 670 9001; Fax: +39 011670 9000;

E-mail: elisa.chiavassa@unito.it such as Candida albicans and M. pachydermatis and can also act upon certain Gram-positive bacteria [9, 10]. Moreover, a synergistic interaction in vitro between PMX and MCZ has been demonstrated against different species of bacteria frequently involved in canine otitis externa [11-13]. Synergy, in this context, can be defined as the increased effectiveness of multiple drugs that, in combination, are more efficient than the cumulative effects of the individual components [14]. Regarding M. pachydermatis, synergy has so far only been demonstrated against one type strain $(M$. pachydermatis CBS 1879) [12]. The aim of the present study was to evaluate the in vitro antifungal activity of the combination of PMX and MCZ against clinical strains of $M$. pachydermatis associated with canine otitis externa.

Five strains of $M$. pachydermatis from dogs with otitis externa, randomly selected from different regions of Italy, were investigated. Ears were sampled through the use of sterile cotton swabs, and yeasts were isolated on Sabouraud Dextrose Agar with chloramphenicol and gentamicine. Identification of these clinical isolates was based on macroscopic and microscopic characteristics [15]. All strains were examined for their in vitro susceptibility to PMX and MCZ as single substances and in combination. A modified CLSI (Clinical and Laboratory Standards Institute) M27-A3 method [16] was employed. Christensen's urea broth medium with Tween 80 and Tween 40 was used, instead of the RPMI 1640 medium suggested by the CLSI $[16,17]$, in order to meet the growth requirements of M. pachydermatis. Uniform yeast suspensions were prepared from 4-day-old colonies subcultured at $37^{\circ} \mathrm{C}$ on Sabouraud Dextrose Agar. Inoculum suspensions were adjusted by spectrophotometer, and the final yeast cell concentration was approximately $1-5 \times 10^{5}$ cells $/ \mathrm{ml}$. Stock suspensions of MCZ (Sigma- 


\section{PMX}

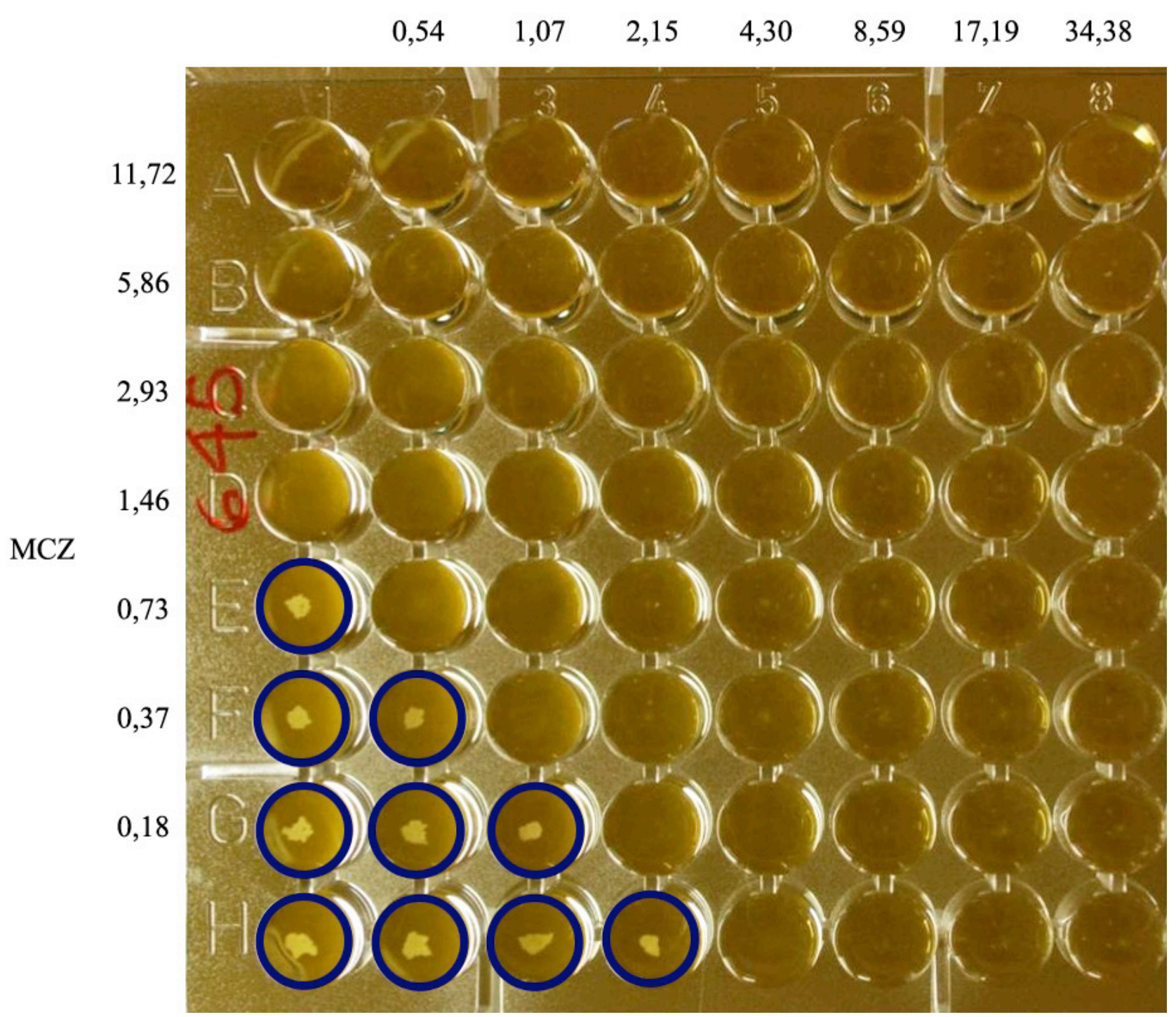

Fig. (1). Test showing synergy between miconazole (MCZ) and polymyxin B (PMX) in the strain of M. pachydermatis VMT 645 Concentration varied from $34.38 \mathrm{mg} / \mathrm{l} \mathrm{PMX}$ combined with $11.72 \mathrm{mg} / \mathrm{l} \mathrm{MCZ}$ to $0.54 \mathrm{mg} / \mathrm{PMX}$ combined with $0.18 \mathrm{mg} / 1 \mathrm{MCZ}-\mathrm{Wells}$ with yeast growth are highlighted (blue circles).

Aldrich, Taufkirchen, Germany) and PMX (Sigma-Aldrich) were prepared in dimethyl sulfoxide. Synergy trials were performed as chequerboard interactions in 96-well plates. Yeasts were added to a twofold serial dilution of a single antibiotic agent or in combination with an identical dilution of the other antibiotic agent. Plates were incubated at $37^{\circ} \mathrm{C}$ and analysed at $48 \mathrm{~h}$ after inoculation. Concentrations tested in combination consisted of equal molar concentrations of PMX and MCZ [13]. They varied from $34.38 \mathrm{mg} / 1$ PMX combined with $11.72 \mathrm{mg} / \mathrm{l} \mathrm{MCZ}$ (corresponding to $24.81 \mathrm{x}$ $10^{-6} \mathrm{~mol} / 1$ of each drug) to $0.54 \mathrm{mg} / \mathrm{l} \mathrm{PMX}$ combined with $0.18 \mathrm{mg} / \mathrm{l} \mathrm{MCZ}$ (corresponding to $0.39 \times 10^{-6} \mathrm{~mol} / \mathrm{l}$ of each drug). The minimum inhibitory concentration (MIC) was read as the lowest concentration of antimicrobial substance which inhibited visible growth, as assessed by using a spectrophotometer (630 nm filter). Each strain was tested on three separate occasions to verify the reproducibility of the results obtained [18]. The fractional inhibitory concentration index (FICi) was calculated as follows: FIC of drug A (MIC of drug A in combination/ MIC of drug A alone) + FIC of drug B (MIC of drug B in combination/MIC of drug B alone). FICi was interpreted as follows: $\leq 0.5=$ synergy; $>$ $0.5-4=$ no interaction; $>4=$ antagonism [19].

MICs of MCZ for M. pachydermatis isolates ranged from 1.46-5.86 mg/l; MIC of PMX for all strains tested was 4.3 $\mathrm{mg} / \mathrm{l}$. If both antimicrobial agents were used in combination, the susceptibility of M. pachydermatis was altered to an MIC of $0.18 \mathrm{mg} / \mathrm{l} \quad(\mathrm{MCZ})$ and 0.54 (PMX) $\mathrm{mg} / \mathrm{l}$, with corresponding $\mathrm{FICi}<0.50$, which indicates a synergistic response, as shown in Fig. (1). Results of the susceptibility tests are summarized in Table $\mathbf{1}$.

As mentioned above, synergy is said to occur when the combination of drugs results in a more efficient response than the cumulative effects of the individual components [14]. In the case of the combination of PMX and MCZ, 
Table 1. The In Vitro Susceptibility of M. pachydermatis Isolates to Miconazole (MCZ) and Polymyxin B (PMX) as Single Substances and in Combination

\begin{tabular}{|c|c|c|c|}
\hline Yeast Strain & MCZ MIC* & PMX MIC & FICi* \\
\hline \hline VMT 645 & 1,46 & 4,3 & 0,4 \\
\hline VMT 622 & 5,86 & 4,3 & 0,2 \\
\hline VMT 620 & 5,86 & 4,3 & 0,2 \\
\hline VMT 601 & 1,46 & 4,3 & 0,4 \\
\hline VMT 605 & 1,46 & 4,3 & 0,4 \\
\hline
\end{tabular}

*MIC, minimun inhibithory concentration (mg/l); FICi, fractional inhibithory concentration index

synergy occurs because PMX is able to increase the efficacy of hydrophobic antibiotics, such as MCZ, by facilitating penetration so that $\mathrm{MCZ}$ can more readily reach the intracellular space in order to carry out its action [20]. MCZ is known to inhibit the synthesis of ergosterol, a bioregulator of membrane integrity in fungal cells [21]. MCZ can also function in its antifungal role by inducing reactive oxygen species which results in fungal cell death $[22,23]$.

Up until now, synergy between PMX and MCZ has been demonstrated against different bacterial species often involved in canine otitis externa, such as Staphylococcus aureus, Pseudomonas aeruginosa and Escherichia coli [11, 12], but in most cases experiments have been conducted on reference strains. Moreover, Pietschmann et al. (2013) have recently shown an in vitro synergy of $\mathrm{PMX}$ and $\mathrm{MCZ}$ against field strains (i.e. strains sampled from dogs with otitis externa) of $E$. coli and $P$. aeruginosa. Regarding fungi, synergy of PMX and MCZ has also been demonstrated against Candida albicans [24] and M. pachydermatis. However, with reference to M. pachydermatis, data has only been collected for one strain, which was, furthermore, a reference strain coming from a fungal collection (M. pachydermatis CBS 1879) [12]. Our data confirm that a synergistic interaction of PMX and MCZ exists against field strains of $M$. pachydermatis. Although further studies on a larger number of strains are necessary for confirmation, these findings support the rationale for applying PMX and MCZ in combination for the treatment of canine otitis externa caused by $M$. pachydermatis. In addition, the fact that these two drugs display a synergistic effect may enable a reduction of their dosage and of the length of treatment, which, in turn, may reduce the risk of the development of drug resistance.

\section{CONFLICT OF INTEREST} Elanco.

Elisa Chiavassa and Andrea Peano are consultants of

\section{ACKNOWLEDGEMENT}

This work was supported by a grant of Elanco Animal Health, division of Eli Lilly Italy S.p.A.

\section{REFERENCES}

[1] Scott DW, Miller WH, Griffin CE. In: Muller and Kirk's Small Animal Dermatology. Otitis externa. Philadelphia: WB Saunders Co. 2001; pp. 1204-35.
[2] Lyskova P, Vydrzalova M, Mazurova J. Identification and antimicrobial susceptibility of bacteria and yeasts isolated from healthy dogs and dogs with otitis externa. J Vet Med A Physiol Pathol Clin Med 2007; 54: 559-63.

[3] Crespo MJ, Abarca ML, Cabanes FJ. Occurrence of Malassezia spp. in the external ear canals of dogs and cats with and without otitis externa. Med Mycol 2002; 40: 115-21.

[4] Jacobson LS. Diagnosis and medical treatment of otitis externa in the dog and cat. J S Afr Vet Assoc 2002; 73: 162-70.

[5] Studdert VP, Hughes KL. A clinical trial of a topical preparation of miconazole, polymyxin and prednisolone in the treatment of otitis externa in dogs. Aust Vet J 1991; 68: 193-35.

[6] Engelen MA, Anthonissens E. Efficacy of non-acaricidal containing otic preparations in the treatment of otoacariasis in dogs and cats. Vet Rec 2000; 147: 567-9.

[7] Schwartz SN, Medoff G, Kobayashi GS, Kwan CN, Schlessinger D. Antifungal properties of polymyxin $\mathrm{B}$ and its potentiation of tetracycline as an antifungal agent. Antimicrob Agents Chemother 1972; $2: 36-40$.

[8] Gale EF, Cundliffe E, Reynolds PE, Richmond MH, Waring MJ. The Molecular Basis of Antibiotic Action. 2rd ed. London: John Wiley \& Sons 1981.

[9] Janssen PAJ, Van Bever WFW. In: Pharmacological and Biochemical Properties of Drug Substances In: Goldberg. ME, Ed. Miconazole. Washington DC, American Pharmaceutical Association 1979; pp. 333-54.

[10] Van Cutsem JM, Thienpont D. Miconazole, a broad-spectrum antimycotic agent with antibacterial activity. Chemotherapy 1972; 17: $392-404$

[11] Cornelissen F, Van den Bossche H. Synergism of the antimicrobial agents miconazole, bacitracin and polymyxin B. Chemotherapy 1983; 29: 419-42.

[12] Pietschmann S, Hoffmann K, Voget M, et al. Synergistic effects of miconazole and polymyxin B on microbial pathogens. Vet Res Commun 2009; 33: 489-505.

[13] Pietschmann S, Meyer M, Voget M, Cieslicki M. The joint in vitro action of polymyxin $\mathrm{B}$ and miconazole against pathogens associated with canine otitis externa from three European countries. Vet Dermatol 2013; 24: 439-97.

[14] Sabath LD. Synergy of antibacterial substances by apparently known substances. Antimicrob Agents Chemother 1968; 7: 210-7.

[15] Guého E, Midgley G, Guillot J. The genus Malassezia with description of four new species. Antonie Van Leeuwenhoek 1996; 69: 337-55.

[16] Peano A, Beccati M, Chiavassa E, Pasquetti M. Evaluation of the antifungal susceptibility of Malassezia pachydermatis to clotrimazole, miconazole and thiabendazole using a modified CLSI M27-A3 microdilution method. Vet Dermatol 2012; 23: 131-5.

[17] Rincón S, Cepero de García MC, Espinel-Ingroff A. A modified Christensen's urea and CLSI broth microdilution method for testing susceptibilities of six Malassezia species to voriconazole, itraconazole, and ketoconazole. J Clin Microbiol 2006; 44: 342931.

[18] Rand KH, Houck HJ, Brown P, Bennett D. Reproducibility of the microdilution checkerboard method for antibiotic synergy. Antimicrob Agents Chemother 1993; 37: 613-5.

[19] Odds FC. Synergy, antagonism, and what the chequerboard puts between them. J Antimicrob Chemother 2003; 52: 1. 
[20] Vaara M. Agents that increase the permeability of the outer membrane. Microbiol Rev 1992; 56(3): 395-411.

[21] Ghannoum MA, Rice LB. Antifungal agents: mode of action, mechanisms of resistance, and correlation of these mechanisms with bacterial resistance. Clin Microbiol Rev 1999; 12: 501-17.

[22] Francois IE, Aerts AM, Cammue BP, Thevissen K. Currently used antimycotics: spectrum, mode of action and resistance occurrence. Curr Drug Targets 2005; 6: 895-907.
[23] Kobayashi D, Kondo K, Uehara N, et al. Endogenous reactive oxygen species is an important mediator of miconazole antifungal effect. Antimicrob Agents Chemother 2002; 46: 3113-7.

[24] Moneib NA. In-vitro activity of commonly used antifungal agents in the presence of rifampin, polymyxin B and norfloxacin against Candida albicans. J Chemother 1995; 7: 525-9.

Received: September 06, 2013

Revised: November 25, 2013

Accepted: November 29, 2013

(C) Chiavassa et al.; Licensee Bentham Open .

This is an open access article licensed under the terms of the Creative Commons Attribution Non-Commercial License (http://creativecommons.org/ licenses/by-nc/3.0/), which permits unrestricted, non-commercial use, distribution and reproduction in any medium, provided the work is properly cited. 